УДК 662.7; 662.641

\title{
УГЛЕРОДИСТЫЙ ОСТАТОК ОТ ТЕРМИЧЕСКОЙ ПЕРЕРАБОТКИ НЕФТЕШЛАМА КАК ОСНОВА ДЛЯ БИО-ТОПЛИВНОЙ КОМПОЗИЦИИ
}

\author{
Табакаев Роман Борисович1, \\ TabakaevRB@tpu.ru
}

\author{
Ларионов Кирилл Борисович², \\ larryk@tpu.ru
}
Ибраева Канипа Талгатовна2,1, kti1@tpu.ru

\author{
Шаненков Иван Игоревич2, \\ swordi@mail.ru
}

\author{
Заворин Александр Сергеевич², \\ zavorin@tpu.ru \\ 1 Тюменский государственный университет, \\ Россия, 625003, г. Тюмень, ул. Володарского, 6. \\ 2 Национальный исследовательский Томский политехнический университет, \\ Россия, 634050, г. Томск, пр. Ленина, 30.
}

\begin{abstract}
Актуальность исследования обуславливается интересом к обеспечению тепловых затрат технологий переработки нефтти за счет побочных продуктов (нефтешлама), а также необходимостью снижения вредных выбросов технологических процессов.

Цель: исследование возможности сжигания углеродного остатка, полученного при паровой газификации нефртешлама, в составе топливной композиции с добавлением торфа.

объект: углеродистый остаток нефтешлама, полученный после паровой газификации нефртяного шлама при температуре $600{ }^{\circ} \mathrm{C}$, и топливная композиция на его основе с добавлением торфа (25 мас. \%).

Методы. Теплотехнические характеристики исследуемых образцов определены согласно ГОСТ Р 55661-2013, 33503-2015 и 55660-2013. Значения теплоты сгорания установлены при помощи калориметра АБК-1 (РЭТ, Россия), элементный состав на анализаторе Vario Micro Cube (Elementar, Германия). Размер частии УОН установлен при помощи растрового электронного микроскопа JSM-6000C (JEOL, Япония). Исследование процесса горения рассматриваемых образиов осуществлено с помощью диффференциального-термического анализатора STA 449 F3 Jupiter (Netzsch, Germany) и экспериментального стенда, оборудованного высокоскоростной видеокамерой FASTCAM CA4 5 (Photron, США). Характерные температуры плавкости золы и её состав определены согласно ГОСТ 2057-94 и ГОСТ 10538-87 соответственно.

Результаты. Углеродистьй остаток нефтешлама имеет превышающую торфф и сопоставимую с бурыми углями теплоту сгорания и довольно низкую температуру воспламенения $\left(220^{\circ} \mathrm{C}\right)$, что обусловлено довольно высоким содержанием летучих веществ ( $\left.V^{d a f}=64,3 \%\right)$. Однако высокие значения зольности ( $\left.A^{d}=60 \%\right)$ и содержания серы ( $\left.S^{d a f}=4,3 \%\right)$ указывают на необходимость утилизации большого количества золы и улавливания окислов серы SOx. Показано, что совместное сжигание углеродистого остатка и торфа (25 мас. \%) позволило снизить количество образующегося зольного остатка. Помимо этого, при добавлении 25 мас. \% суховского торфа удалось снизить количество образующихся выбросов $\mathrm{SO}_{2}$ более чем в 3 раза. Этот эфрфект обусловлен взаимодействием газовой фазы с минеральной частью торфа, а именно, с карбонатами кальция и магния.
\end{abstract}

\section{Ключевые слова:}

Нефтешлам, углеродистый остаток, высокоминерализированный торф,

топливная композиция, сжигание, выбросы оксидов серы.

\section{Введение}

В настоящее время нефть является одним из наиболее востребованных видов энергоносителей в мире [1]. Её добыча, транспортировка, хранение и переработка сопровождаются образованием значительного количества нефтешламовых отходов [2-4], имеющих высокий класс опасности [3]. Состав нефтешламовых отходов зависит от своего технологического происхождения. Как правило, данный тип отхода представляет сложную смесь воды, нефтепродуктов, минеральных примесей и различных отложений (песок, глина, ил и т. п.) [5]. Исследования различных видов нефтешламовых отходов, полученных с маслоотделительных установок, резервуаров для хранения топлива, трубоповодов, цистерн и их промывочных систем [6], показали, что основным отличием является различное содержание воды и механических примесей.

Одним из современных подходов переработки нефтешламовых отходов является их термическое преобразование методами пиролиза или газификации [2-4, 7] с получением полезных продуктов в виде жидких углеводородов, синтез-газа и углеродистого остатка. Перечисленные процессы относятся, как правило, к аллотермическому типу [8], по причине чего образующийся углеродистый остаток используют в качестве вторичного энергоресурса для компенсации энергетических затрат. 
Однако использование углеродистых остатков, полученных при термической переработке нефтешламов, в качестве топлива технологически ограничено высоким содержанием серы и зольности. При сжигании серосодержащего топлива образуются сернистый $\left(\mathrm{SO}_{2}\right)$ и серный $\left(\mathrm{SO}_{3}\right)$ ангидриды, условно обозначаемые $\mathrm{SO}_{\mathrm{x}}$ [9]. Оксиды серы и образующиеся при их контакте с парами воды кислоты $\left(\mathrm{H}_{2} \mathrm{SO}_{3}\right.$ и $\left.\mathrm{H}_{2} \mathrm{SO}_{4}\right)$ оказывают вредное воздействие на здоровье людей и живых организмов, являются причиной гибели растений, снижения урожайности сельскохозяйственных культур, закисления водоемов. Кроме того, оксиды серы являются причиной коррозии стальных конструкций $[10,11]$ и разрушения различных строительных материалов [12, 13]. С целью сокращения выбросов серы обычно используют следующие подходы: 1) предварительное снижение содержание серы в энергетическом топливе (замещение части серосодержащего топлива сырьем без серы, например, биомассой $[14,15]$, обессеривание [16], добавка к топливу карбонатов кальция или магния [17-19]); 2) внутритопочные методы (например, распыление внутри топочного устройства извести $[20,21]) ; 3)$ сероулавливающие установки для очистки дымовых газов (например, аммиачно-циклические, аммиачноозонные, магнезитово-циклические и др. [22, 23]).

Наибольшее распространение в мире получила десульфуризация дымовых газов в сероулавливающих установках. В настоящее время известно более 80-ти модификаций способов удаления $\mathrm{SO}_{2}$ из дымовых газов, реализованных в США, Японии, Германии, Австрии и других странах. Всего в мире оснащено сероочистными установками оборудование суммарной мощностью более 135 ГВт [24]. Однако этот вид снижения $\mathrm{SO}_{\mathrm{x}}$ приводит к повышению стоимости строительства ТЭС на 25-30\% и на 5-15\% увеличивает себестоимость тарифов [25].

Перспективным направлением в настоящее время является снижение вредных выбросов за счет сжигания топливных композиций с добавлением биомассы. Исследования ряда авторов [26, 27] показывают эффективность совместного сжигания угля и древесных отходов, при котором наблюдалось снижение выбросов $\mathrm{SO}_{\mathrm{x}}$ и $\mathrm{NO}_{\mathrm{x}}$. Положительный эффект снижения вредных выбросов достигнут при смешивании табачного стебля и высокосернистого угля [28], в результате чего авторы добились значительного снижения выбросов $\mathrm{SO}_{2}$. При этом в качестве оптимальных условий смешивания предлагается вариант добавления до $20 \%$ табачного стебля. В работе [29] представлены результаты положительного влияния совместного использования угольного шлама и биомассы (древесина и солома) в качестве топливной композиции: по мере увеличения доли биомассы в композиции эмиссия $\mathrm{SO}_{2}$ постепенно снижалась, достигнув своего минимального значения при 70 мас. \%.

Механизм снижения количества вредных выбросов при сжигании топливных композиций до сих пор полностью не изучен. Это обусловлено как широким разбросом в органическом и минералогическом составах сжигаемых топлив (угля и биомассы), так и различными условиями сжигания (пылевидное, слоевое, кипящий слой). Однако в ряде работ [30] авторы отмечают, что снижение вредных выбросов происходит за счет взаимодействия оксидов серы с минеральной частью биомассы, в результате которого в зольном остатке образуются соли серной и сернистой кислот. Эти процессы особенно интересны при рассмотрении топливных композиций с добавлением высокоминерализированных видов биомассы, например, торфа.

Торф - это органоминеральная масса, образовавшаяся в процессе перегнивания остатков болотных растений. Зольность торфа в зависимости от растений-торфообразователей и его географического положения может находиться в широком диапазоне значений - от 4,4 до 25,0 \% [31]. В некоторых странах Европейского союза торф играет довольно серьезную роль в топливно-энергетическом балансе: в Финляндии и Ирландии доля торфа составляет 5-7 \%, Эстонии 1,9 \%, Белоруссии - 1,6 \% и Швеции - 0,7 \% [32, 33].

Однако на территории Российской Федерации торф в основном используется для нужд сельского хозяйства, хотя имеет колоссальный потенциал для энергетического применения в качестве топлива: наша страна является мировым лидером по величине его запасов (30,8 млрд т при условной влажности $40 \%$, или более 10,7 млрд т при пересчете на условное топливо). При этом около $60 \%$ от российских запасов по технологическим факторам оценены как потенциально извлекаемые [34].

В связи с вышеописанным целью настоящей работы является исследование возможности сжигания углеродного остатка, полученного при паровой газификации нефтешлама, в составе топливной композиции с добавлением торфа.

\section{Методика исследования}

Объект исследования

В качестве объектов исследования рассмотрены: твердый углеродистый остаток (УОН), полученный после паровой газификации нефтяного шлама при температуре $600{ }^{\circ} \mathrm{C}$, и топливная композиция (ТК) на его основе с добавлением торфа (25 мас. \%). Размер частиц УОН, установленный при помощи растрового электронного микроскопа JSM-6000C (JEOL, Япония), не превышает 100 мкм (рис. 1).

В качестве добавки при изготовлении топливной композиции выбран торф месторождения Суховское (Россия, Томская область). Разведанные запасы месторождения, согласно [35], составляют более 19 млн т (при влажности торфа $40 \%$ ). Суховской торф относится к низинному типу и обладает следующими характеристиками: $A^{d}=22,8 \%, W^{a}=9,9 \%, V^{d a f}=74,8 \%$, $Q_{i}^{r}=11,8$ МДж/кг, $S^{d a f}=0,2 \%$ [36]. В ранее проведенных исследованиях [36, 37] показано, что зольный остаток торфа относится к тугоплавкому виду (начальная температура деформации золы составляет $\left.1450{ }^{\circ} \mathrm{C}\right)$. Кроме того, по результатам рентгенофазового анализа торфа в минеральной части отмечено преобладание кальцита $\left(\mathrm{CaCO}_{3}\right)$ и кварца $\left(\mathrm{SiO}_{2}\right)$. 


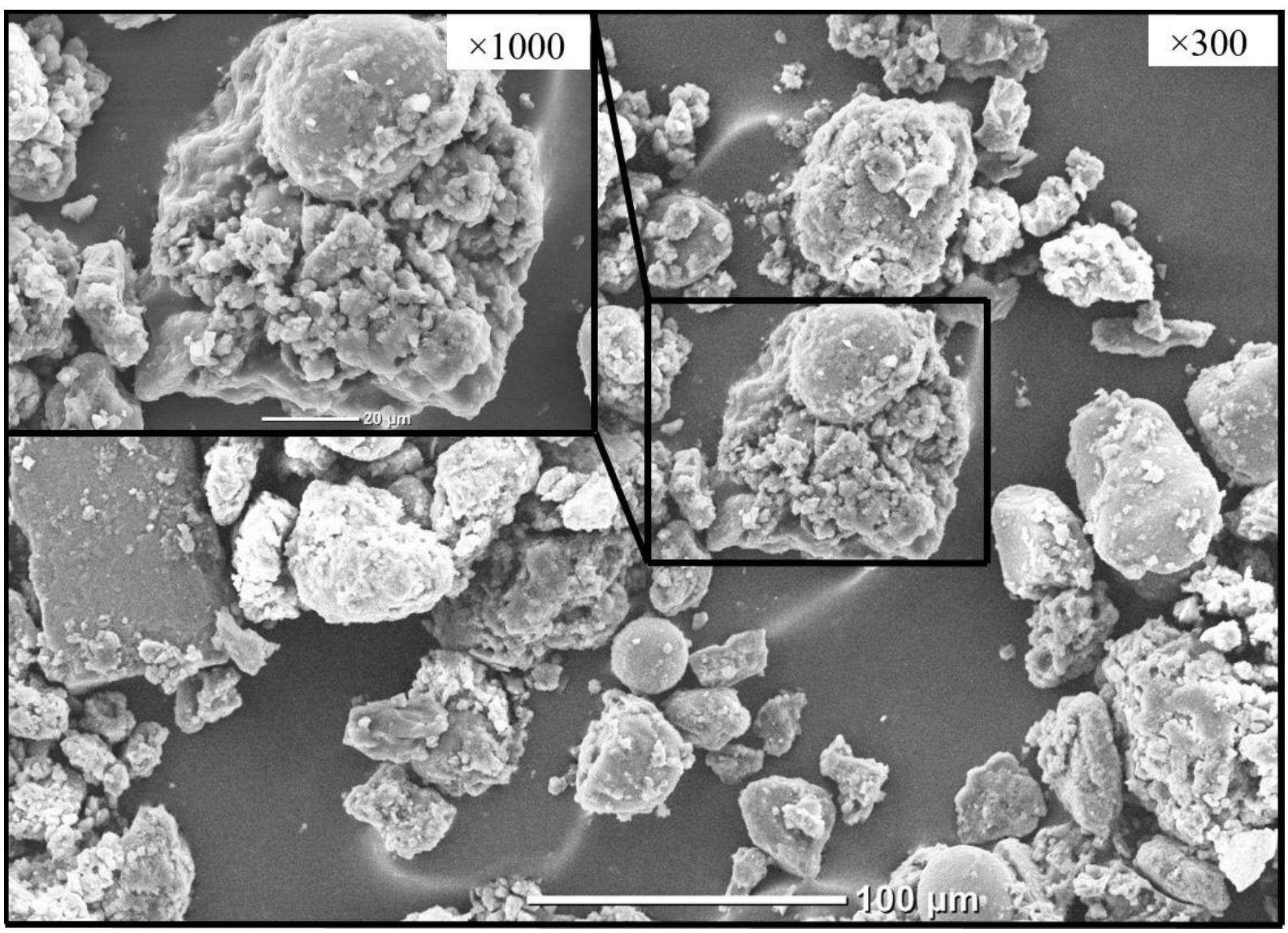

Pис. 1. РЭМ-изображение частии УОН

Fig. 1. REM-image of the carbon residue particles

Теплотехнические характеристики

Теплотехнические характеристики УОН и ТК на его основе с добавлением торфа определены согласно ГОСТ Р 33503-2015, ГОСТ 55661-2013 и ГОСТ Р 55660-2013. Элементный состав органической части исследуемых образцов установлен при помощи анализатора Vario Micro Cube (Elementar, Германия), значение теплоты сгорания - на бомбовом калориметре АБК-1 (РЭТ, Россия).

\section{Дифференциально-термический анализ}

Исследование процесса окисления рассматриваемых образцов осуществлялось с помощью дифференциального-термического анализатора STA 449 F3 Jupiter (Netzsch, Germany). Анализ проводился при скорости нагрева $10^{\circ} \mathrm{C} /$ мин в корундовом тигле до температуры $1000{ }^{\circ} \mathrm{C}$. Образец массой 7-8 мг распределялся ровным слоем по дну тигля и помещался в поток окислительной среды (кислород). Скорость газового потока составляла 150 мл/мин. Все эксперименты проводились в условиях атмосферного давления.

Температуру воспламенения топлива определяли по кривым термогравиметрического (ТГ) и дифференциального термического (ДТА) анализов. При синхронном изменении сигналов ТГ и ДТА (отклонение прямой в сторону экзотермического эффекта) строили вспомогательные касательные прямые, по пересечению которых устанавливали значение соответствующей изменению температуры (рис. 2).

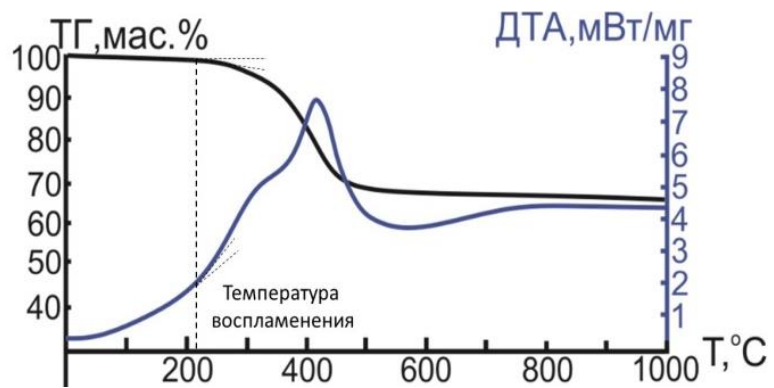

Рис. 2. Вспомогательные построения при определении температуры воспламенения по кривым термогравиметрического и дифференциильного термического анализов

Fig. 2. Auxiliary constructions for determining the ignition temperature from the curves of thermogravimetric and differential thermal analysis

Кроме того, в настоящей работе выполнено качественное определение состава газообразных продуктов термического разложения (в частности $\mathrm{SO}_{2}$ $(\mathrm{m} / \mathrm{z}=64))$. Анализ проводился с помощью сопрягаемого квадрупольного масс-спектрометра QMS 403 D Aeolos (Netzsch, Germany). Сравнение величин выбросов оксидов серы, образующихся при сжигании УО и ТК на его основе, осуществлялось путем сопоставления подынтегральной площади $\mathrm{MC}$-профиля выделения $\mathrm{SO}_{2}$. 


\section{Определение характерных температур плавкости золы}

Характерные температуры плавкости золы определяли согласно ГОСТ 2057-94. Эксперименты проводили по следующей схеме: на первоначальном этапе осуществляли подготовку пробы - смешивали измельченную золу и $10 \%$-ый водный раствор декстрина; однородную смесь помещали в изготовленную емкость в форме трехгранной пирамиды для затвердевания; полученную пирамиду, размещенную на платиновой пластине, помещали в криптоловую печь с постепенным нагревом со скоростью $10-15^{\circ} \mathrm{C}$ в минуту до температуры $1500{ }^{\circ} \mathrm{C}$ (рис. 3). В ходе эксперимента регистрировались температуры, при которых происходили деформационные изменения образца, соответствующие трем стадиям (начало деформации $\left(t_{A}\right)$, размягчение $\left(t_{B}\right)$ и переход в жидкоплавкое состояние $\left.\left(t_{C}\right)\right)$.

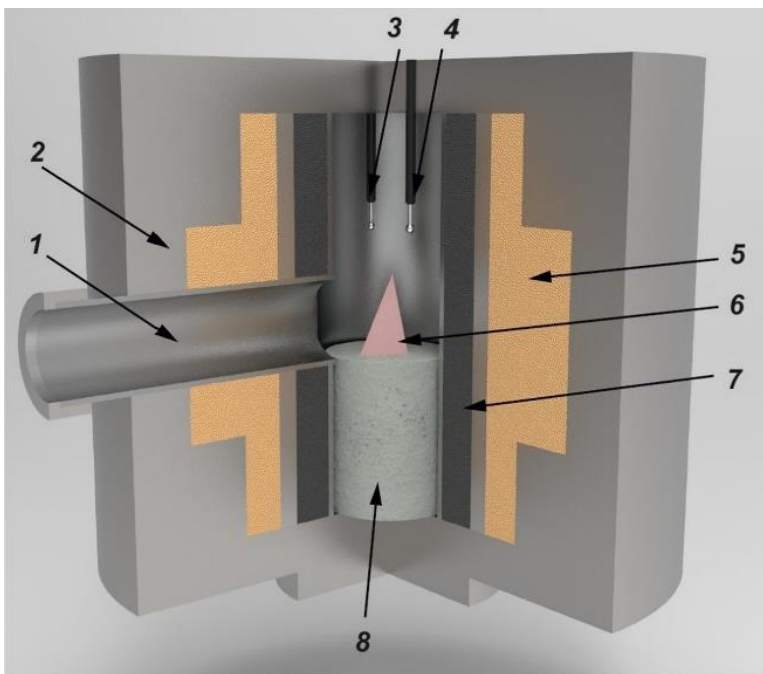

Рис. 3. Экспериментальная установка: 1 - визирная трубка; 2 - корпус печи; 3 - измерительная термопара (ВР-1); 4 - контрольная термопара (ПП-1); 5 - шамотная крошка; 6- пирамидка из золы; 7 - криптоловая засыпка; 8 - муфельная подставка

Fig. 3. Experimental setup: 1 - swirl tube with a lens; 2 - unit body; 3 - measuring thermocouple (WR-1); 4 - control thermocouple (PP-1); 5 - heat-insulating filling; 6 - pyramid of ash; 7 - cryptolite filling; 8 - muffle stand

\section{Анализ химического состава золы}

Химический состав золы определяли согласно ГОСТ 10538-87 «Топливо твердое. Методы определения химического состава золы». Используемые методы для определения компонентов золы $\left(\mathrm{SiO}_{2}, \mathrm{SO}_{3}\right.$,
$\mathrm{Al}_{2} \mathrm{O}_{3}, \mathrm{Fe}_{2} \mathrm{O}_{3}, \mathrm{CaO}$ и $\mathrm{MgO}, \mathrm{TiO}_{2}$ ) подробно описаны авторами в работе [36].

\section{Экспериментальное сжигание}

Исследование процесса горения проводилось с помощью экспериментального стенда, более подробное описание которого приведено авторами в предыдущей работе [38]. Температура греющей среды составляла $800^{\circ} \mathrm{C}$. Визуализация процесса горения выполнена с помощью высокоскоростной видеокамеры FASTCAM CA4 5 (Photron, СШA).

\section{Результаты исследования}

Характеристики углеродистого остатка нефтешлама

В табл. 1 представлены результаты определения теплотехнических характеристик УОН. Видно, что полученный при переработке продукт, несмотря на высокое значение зольности $(A=60 \%)$, имеет превышающую торф $(6,66-9,99$ МДж/кг $[39,40])$ и сопоставимую с бурыми углями (6,38-19,80 МДж/кг [40]) теплоту сгорания $\left(Q_{i}^{r}=14,2\right.$ МДж/кг). Выход летучих при пересчете на сухую беззольную массу имеет довольно высокое для топлива значение, характерное для высокореакционных топлив, следствием чего является низкая температура начала воспламенения $\left(220{ }^{\circ} \mathrm{C}\right)$, установленная при помощи ДТА (рис. 4).

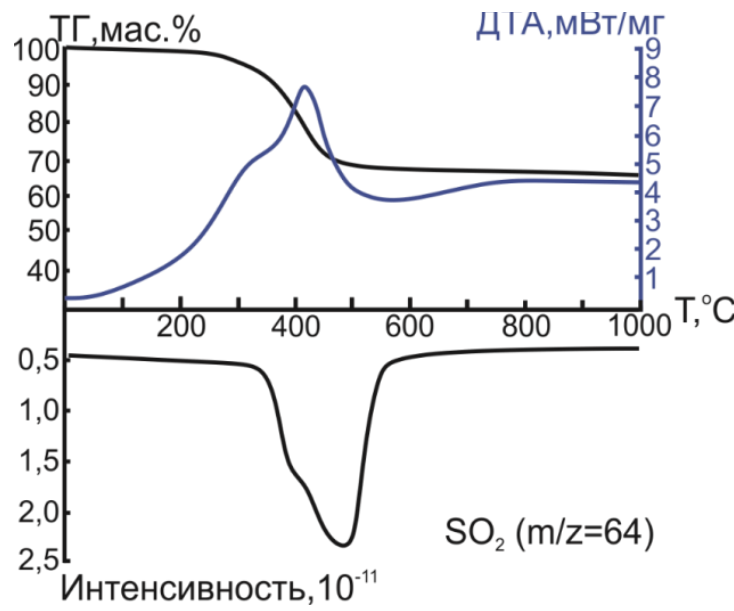

Pис. 4. Кривые термогравиметрического (ТГ) и дифференциального термического (ДТА) анализов при синхронной масс-спектроскопии газовых продуктов в прочессе нагрева УОН в окислительной среде до температуры $100{ }^{\circ} \mathrm{C}$

Fig. 4. Curves of thermogravimetric (TG) and differential thermal (DTA) analysis during synchronous mass spectroscopy of gas products in the process of heating the carbonaceous residue in an oxidizing medium to a temperature of $1000^{\circ} \mathrm{C}$

Таблица 1. Теплотехнические характеристики и элементный состав углеродистого остатка нефтешлама

Table 1. Thermotechnical characteristics and elemental composition of carbon residue of oil sludge

\begin{tabular}{|c|c|c|c|c|c|c|c|c|c|}
\hline \multirow[t]{2}{*}{$\begin{array}{l}\text { Проба } \\
\text { Sample }\end{array}$} & \multirow[t]{2}{*}{$\begin{array}{c}\text { Влажность } \\
\text { Moisture, } \\
W^{r}, \%\end{array}$} & \multirow[t]{2}{*}{$\begin{array}{c}\text { Зольность на } \\
\text { сухую массу } \\
\text { Ash on dry ba- } \\
\quad \operatorname{sis} A^{d}, \%\end{array}$} & \multirow[t]{2}{*}{$\begin{array}{l}\text { Выход летучих } \\
\text { веществ } \\
\text { Yield of vola- } \\
\text { tile sub } \\
\text { stances } V^{\text {daf }}, \%\end{array}$} & \multirow[t]{2}{*}{$\begin{array}{c}\text { Низшая теплота } \\
\text { сгорания } Q_{i}^{r}, \\
\text { МДжж/кг } \\
\text { Low heating value } \\
Q_{i}^{r}, \mathrm{MJ} / \mathrm{kg}\end{array}$} & \multicolumn{5}{|c|}{$\begin{array}{c}\text { Элементный состав на сухую } \\
\text { беззольную массу*, \% } \\
\text { Elemental composition per } \\
\text { combustible mass*, \% }\end{array}$} \\
\hline & & & & & $C^{\text {daf }}$ & $H^{d a f}$ & $N^{\text {daf }}$ & $S^{\text {daf }}$ & $O^{d a f}$ \\
\hline $\begin{array}{c}\text { Углеродистый } \\
\text { остаток } \\
\text { Carbon residue }\end{array}$ & 0,6 & 60,0 & 64,3 & 14,2 & 63,2 & 5,3 & 0,8 & 4,3 & 26,4 \\
\hline
\end{tabular}


Необходимо отметить довольно высокое содержание серы в пересчете на горючую массу топлива, равное $S^{d a f}=4,3 \%$ (табл. 1), что приводит к образованию выбросов $\mathrm{SO}_{2}$ при сжигании (рис. 4).

При изучении плавкостных характеристик золы (рис. 5) установлено, что зольный остаток, полученный при сжигании УОН, относится к среднеплавкому типу $\left(t_{c}>1250{ }^{\circ} \mathrm{C}\right)$. Однако низкие значения темпера- туры начала деформации $\left(t_{A}\right)$ и величина отношения кислых компонентов к основным $\Sigma K / \Sigma O$ (табл. 2) накладывают ограничения на температуру дымовых газов, образующихся при сжигании УОН, на выходе из топочной камеры - не более $1050{ }^{\circ} \mathrm{C}[41]$. Это условие необходимо учитывать при тепловом расчете котельного агрегата и конструировании топливосжигающего оборудования.
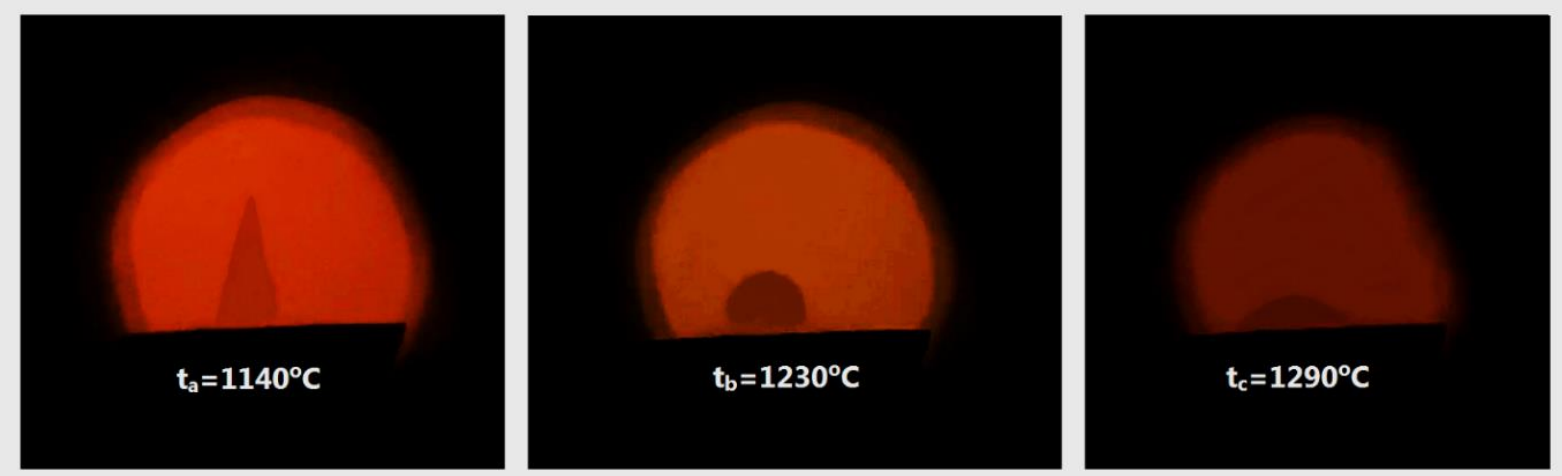

Pис. 5. Плавкостные характеристики зольного остатка, полученного при сжигании УОН

Fig. 5. Fusible characteristics of the ash residue obtained during CROS combustion

Таблица 2. Состав основных компонентов золь УОН

Table 2. Composition of the main components of CROS ash

\begin{tabular}{|c|c|c|c|c|c|c|c|c|}
\hline \multirow{2}{*}{ Проба/Sample } & \multicolumn{7}{|c|}{ Состав золы, \%/Ash composition, \% } & \multirow{2}{*}{$\sum K / \Sigma O$} \\
\cline { 2 - 9 } & $\mathrm{SiO}_{2}$ & $\mathrm{Al}_{2} \mathrm{O}_{3}+\mathrm{TiO}_{2}$ & $\mathrm{Fe}_{2} \mathrm{O}_{3}$ & $\mathrm{SO}_{3}$ & $\mathrm{CaO}$ & $\mathrm{MgO}$ & $\mathrm{K}_{2} \mathrm{O}+\mathrm{Na}_{2} \mathrm{O}$ & \\
\hline УOH/CROS & 62,7 & 9,7 & 12,4 & 2,3 & 5,7 & 2,9 & 3,9 & 5,792 \\
\hline
\end{tabular}

\section{Сжигание нефтешлама и топливной композиции} на его основе

На рис. 6 представлены кадры высокоскоростной видеосъемки, визуализирующие процесс горения исходного УОН и ТК на его основе при температуре греющей среды $t_{g}=800{ }^{\circ} \mathrm{C}$. Подготовленная ТК имеет следующие характеристики: зольность $\left(A^{d}\right)-50,7 \%$, выход летучих веществ $\left(V^{d a f}\right)-66,9 \%$, низшая теплота сгорания $\left(Q_{i}^{r}\right)-13,6$ МДж/кг, содержание углерода $\left(C^{d a f}\right)-60,4 \%$, содержание водорода $\left(H^{d a f}\right)-5,6 \%$, содержание азота $\left(N^{d a f}\right)$ - 1,5\%, содержание серы $\left(S^{d a f}\right)-3,3 \%$, содержание кислорода $\left(O^{d a f}\right)-29,2 \%$.

Процесс горения можно разделить на несколько стадий физико-химического преобразования, которые связаны с нагревом, испарением влаги, термодеструкцией и началом выделения летучих соединений, смешением горючих газов с окислительной средой и последующим окислением образующегося коксового остатка. При этом для обоих рассматриваемых образцов процесс горения протекает с образованием видимого пламени вблизи насыпки образца. Это связано с интенсивным выделением летучих веществ в виде горючих газофазных продуктов с поверхности образца. Так, вблизи насыпки формируется паровое облако с горючей смесью, в результате чего происходит ее газофазное зажигание. Следом за газофазным зажиганием наблюдается образование постепенно развивающегося пламени вокруг насыпки ( $\tau$ до 10 c). Отли- чием процесса горения исследуемых образцов является время зажигания, продолжительность которого для образца с содержанием 25 мас. \% торфа короче более чем в 2 раза.

На стадии окисления коксового остатка $(\tau=10-20 \mathrm{c})$ можно наблюдать изменение формы насыпки, что выражается в уменьшении ее объема ввиду плавления образующегося зольного остатка.

Как можно видеть по данным дифференциального термического анализа, совмещенного с массспектроскопией (рис. 7), при совместном сжигании торфа и углеродистого остатка количество образовавшихся оксидов серы значительно меньше: при сопоставлении интегральных площадей $\mathrm{SO}_{2}$ от сжигания ТК и УОН установлено, что количество образовавшихся оксидов снижается более чем в 3 раза. Это можно объяснить взаимодействием газовой фазы с минеральной частью торфа. Как показано в [36], основу минеральной части торфа составляет оксид кремния и карбонаты кальция и магния, что позволяет предположить следующий механизм взаимодействия:

$$
\begin{gathered}
\mathrm{CaCO}_{3} \rightarrow \mathrm{CaO}+\mathrm{CO}_{2} \uparrow, \\
\mathrm{CaO}+\mathrm{SO}_{3} \rightarrow \mathrm{CaSO} \mathrm{Ca}_{4}, \\
\mathrm{MgCO}_{3} \rightarrow \mathrm{MgO}+\mathrm{CO}_{2} \uparrow, \\
\mathrm{MgO}+\mathrm{SO}_{3} \rightarrow \mathrm{MgSO}_{4} \downarrow .
\end{gathered}
$$


Таблица 3. Состав основных компонентов золы ТК

Table 3. Composition of the main components of FC ash

\begin{tabular}{|c|c|c|c|c|c|c|c|c|}
\hline \multirow{2}{*}{ Проба/Sample } & \multicolumn{7}{|c|}{ Состав золы/Ash composition, \% } & \multirow{2}{*}{$\sum K / \sum O$} \\
\hline & $\mathrm{SiO}_{2}$ & $\mathrm{Al}_{2} \mathrm{O}_{3}+\mathrm{TiO}_{2}$ & $\mathrm{Fe}_{2} \mathrm{O}_{3}$ & $\mathrm{SO}_{3}$ & $\mathrm{CaO}$ & $\mathrm{MgO}$ & $\mathrm{K}_{2} \mathrm{O}+\mathrm{Na}_{2} \mathrm{O}$ & \\
\hline $\begin{array}{c}\text { Топливная композиция } \\
\text { (углеродистый остаток } 75 \% \text { +торф } 25 \% \text { ) } \\
\text { Fuel composition (carbon residue } 75 \%+\text { +peat } 25 \% \text { ) }\end{array}$ & 49,1 & 12,6 & 11,9 & 6,7 & 12,5 & 3,2 & 4,0 & 12,136 \\
\hline
\end{tabular}

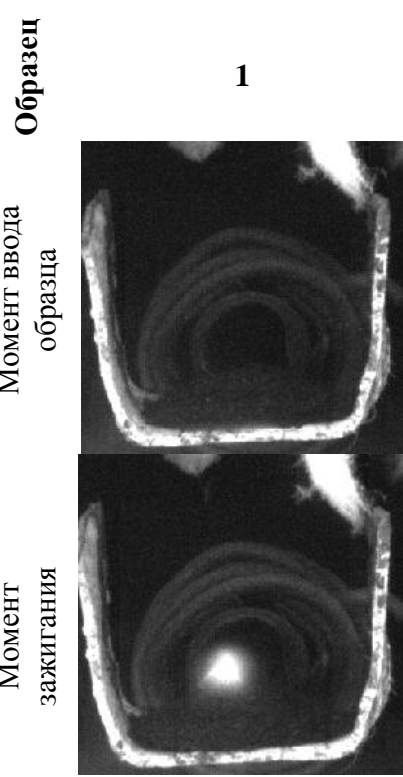

$1,65 \mathrm{c}$

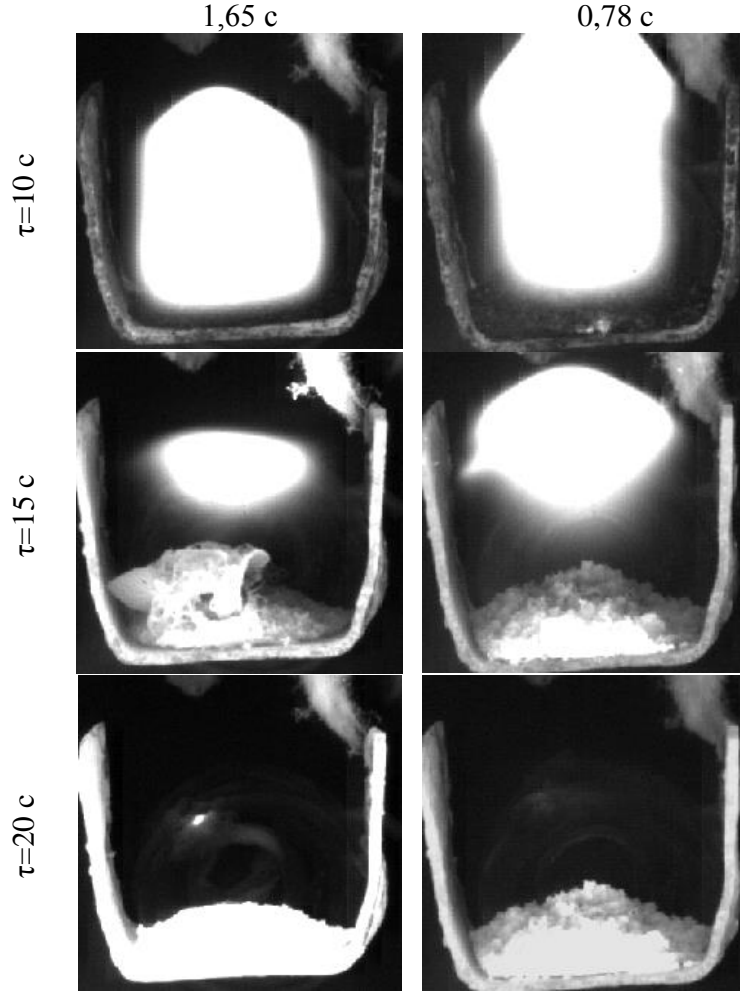

Pис. 6. Кадры начальной стадии процесса горения УОН и ТК на его основе при температуре греющей среды $t_{g}=800{ }^{\circ} \mathrm{C}: 1-\mathrm{YOH}, 2-$ TK $(25$ мас. \% торфа)

Fig. 6. Frames of the initial stage of the combustion of CROS and FC based on it at the temperature of the heating medium $t_{g}=800{ }^{\circ} \mathrm{C}: 1-C R O S, 2-F C$ (25 wt. \% of peat)

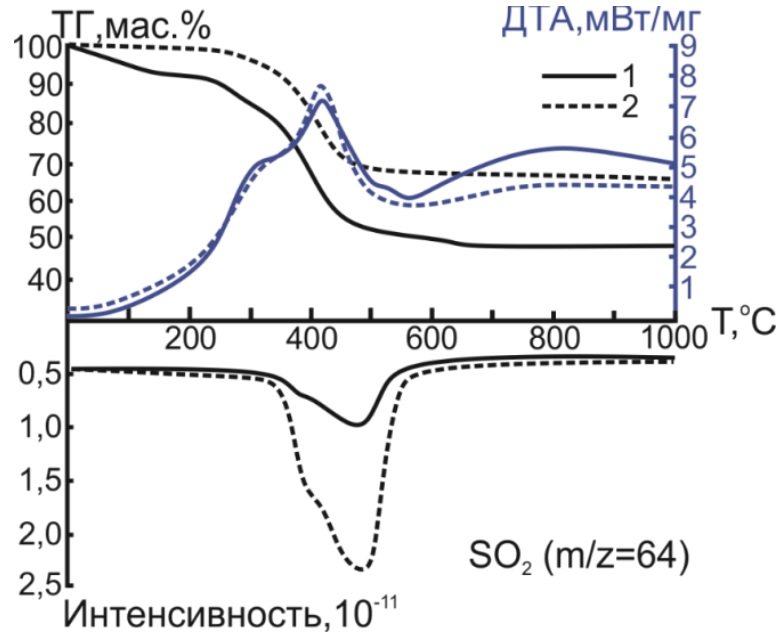

Pис. 7. Кривые термогравиметрического (ТГ) и дифференциального термического (ДТА) анализов при синхронной масс-спектроскопии газовых продуктов в прочессе нагрева УОН и ТК на его основе в окислительной среде до температуры $1000{ }^{\circ} \mathrm{C}: 1-\mathrm{TK}, 2-У О Н$ (для сравнения)

Fig. 7. Curves of thermogravimetric (TG) and differential thermal (DTA) analysis during synchronous mass spectroscopy of gaseous products in heating the carbonaceous residue and the fuel composition in an oxidizing environment $\left(30-1000{ }^{\circ} \mathrm{C}\right): 1$ - the fuel composition, 2 - the carbon residue (for comparison)

Подтверждением этому служит и состав золы, изученный после сжигания топливной композиции (табл. 3). При сравнении данных табл. 2, 3 видно, что в зольном остатке ТК содержание оксида серы увеличилось в 2,5 раза. Кроме того, произошло увеличение оксидов кальция и магния в 2,2 и 1,1 раза, соответственно, за счет минеральной части добавленного торфа.

\section{Заключение}

При изучении характеристик УОН, полученного при паровой газификации нефтешлама при температуре $600{ }^{\circ} \mathrm{C}$, применительно к энергетическому использованию установлено, что данный продукт имеет превышающую торф и сопоставимую с бурыми углями теплоту сгорания $\left(Q_{i}^{r}=14,2\right.$ МДж/кг). Температура воспламенения УОН составляет порядка $220^{\circ} \mathrm{C}$, что обусловлено довольно высоким содержанием летучих веществ $\left(V^{d a f}=64,3 \%\right)$. Однако высокие значения зольности $\left(A^{d}=60 \%\right)$ и содержания серы $\left(S^{d a}=4,3 \%\right)$ указывают на необходимость утилизации большого количества золы и улавливания окислов серы $\mathrm{SO}_{\mathrm{x}}$.

Рассмотрена возможность сжигания углеродистого остатка в составе топливной композиции при до- 
бавлении высокоминерализированной биомассы на примере торфа Суховского месторождения $(A=22,8 \%)$. Показано, что совместное сжигание углеродистого остатка и торфа (25 мас. \%) позволило снизить количество образующегося зольного остатка до 50,7\% (рис. 7). Помимо этого, при добавлении 25 мас. \% суховского торфа в процессе сжигания ТК удалось снизить количество образующихся выбросов $\mathrm{SO}_{2}$ более чем в 3 раза. Этот эффект обусловлен взаимодействием газовой фазы с минеральной частью торфа, а именно - с карбонатами кальция и магния. Таким образом, перспективным направлением развития дальнейших исследований представляется поиск

\section{СПИСОК ЛИТЕРАТУРЫ}

1. IEA Online Data Services. Renewables Information // IEA. URL: https://www.iea.org/fuels-and-technologies/electricity.html (дата обращения 11.08.2021).

2. Hazardous elements flow during pyrolysis of oily sludge / J. Li, F. Lin, L. Xiang, F. Zheng, L. Che, W. Tian, G. Chen // Journal of Hazardous Materials. - 2021. - V. 409. - 124986.

3. Assessment of the energy recovery potential of oil sludge through gasification aiming electricity generation / Y.C. Santiago, A.M. González, O.J. Venturini, D.M.Y. Maya // Energy. - 2021. V. 215. - 119210 .

4. Experimental study on kinetic characteristics of oil sludge gasification / Z. Chu, Z. Gong, Z. Wang, H. Zhang, J. Wu, Z. Wang, H. Wang // Asia-Pacific Journal of Chemical Engineering. - 2021. - V. 16. - P. 1-11.

5. Mazlova E.A., Meshcheryakov S.V. Ecological characteristics of oil sludges // Chemistry and technology of fuels and oils. - 1999. V. 35. - P. 49-53.

6. Zhuravskii G.I. Fuel from oil sludges // Journal of Engineering Physics and Thermophysics. - 2019. - V. 92. - P. 940-947.

7. Zhou L., Jiang X., Liu J. Characteristics of oily sludge combustion in circulating fluidized beds // Journal of hazardous materials. 2009. - V. 170. - P. 175-179.

8. Autothermal and allothermal pyrolysis in a continuous fixed bed reactor / M. Milhé, L. Van de Steene, M. Haube, J.M. Commandré, W.F. Fassinou, G. Flamant // Journal of Analytical and Applied Pyrolysis. - 2013. - V. 103. - P. 102-111.

9. Разва А.С. Методы и технологии очистки дымовых газов от оксидов серы // Студопедия. 2010. URL: http://studopedia.ru/5_16593_metodiochistki-dimovih-gazov-otoksidov-seri. html (дата обращения 19.08.2021).

10. Ding Q., Tang X.F., Yang Z.G. Failure analysis on abnormal corrosion of economizer tubes in a waste heat boiler // Engineering Failure Analysis. - 2017. - V. 73. - P. 129-138.

11. Соловьев А.К., Михеев В.О., Пуликов П.С. Очистка дымовых газов от оксидов серы // Вестник Сибирского государственного индустриального университета. - 2014. - № 3 (9). - С. 33-36.

12. Yeau K.Y., Kim E.K. An experimental study on corrosion resistance of concrete with ground granulate blast-furnace slag // Cement and Concrete Research. - 2005. - V. 35 - - P. 1391-1399.

13. Голубых Н.Д., Жеребятьева Т.В., Корнеев А.Д. Биодеструкция гидросиликатов строительных материалов // Научный вестник Воронежского государственного архитектурно-строительного университета. Строительство и архитектура. - 2009. - № 3. C. 54-60.

14. Lasek J.A., Kazalski K. Sulfur self-retention during cocombustion of fossil fuels with biomass // Energy \& fuels. - 2014. - V. 28. P. 2780-2785.

15. Гриценко А.В., Внукова Н.В., Позднякова Е.И. Совместное сжигание продуктов пиролиза шин и древесных пеллет // Энергетика. Известия высших учебных заведений и энергетических объединений СНГ - 2021. - Т. 64 - № 4. - С. 363-376.

16. Исследование и внедрение процессов газификации углей и биомассы с целью замещения природного газа / И.Н. Карп, Е.П. Марцевой, К.Е. Пьяных, Т.А. Антощук, К.К. Пьяных // Энерготехнологии и ресурсосбережение. - 2014. - № 4. C. 3-13. оптимального соотношения углеродистого остатка и торфа, обеспечивающего наименьшие выбросы оксидов серы при сжигании.

Работа выполнена при поддержке Российского фонда фундаментальных исследований (проект № 19-38-90148). Аналитические измерения проведены в лаборатории ресурсоэффективных технологий термической переработки биомассы в рамках государственного задания (тема: «Разработка безотходной технологии термической переработки биомассы в твердые и газообразные продукты для обеспечения энергетики и промышленности снижающей «углеродный след» продукиией»).

17. Study on the migration characteristics of sulfur and nitrogen during combustion of oil sludge with $\mathrm{CaO}$ additive / $\mathrm{H}$. Zhang, Z. Gong, L. Liu, Z. Wang, X. Li // Energy \& Fuels. - 2020. V. 34. - P. 6124-6135.

18. Нейтрализация соединений серы при фильтрационном горении сернистых углей путем добавки твердых кальцийсодержащих материалов / В.М. Кислов, Ю.Ю. Цветкова, М.В. Цветков, Е.Н. Пилипенко, М.В. Салганская // Горение и плазмохимия. - 2020. - Т. 18. - № 3. - С. 127-132.

19. Effects of $\mathrm{CaO}-\mathrm{MgCO}_{3}$ on the combustion behavior and emission properties of $\mathrm{SO}_{2}$ and $\mathrm{NO}_{\mathrm{x}}$ during semi-coke combustion / G.L. Wu, R.T. Guo, Y.Z. Liu, C.P. Duan, Y.F. Miao, J.W. Gu, W.G. Pan // Chemical Papers. - 2021. - V. 75. - P. 2495-2501.

20. Арбузов В.А., Исанова Б.Х., Белякова М.О., Задиранов А.Н. Очистка дымовых газов ТЭЦ от оксидов серы и азота // Литьё и металлургия. - 2009. - № 3. - С. 99-103.

21. Combustion properties and desulfurization of high sulfur containing indian and nepali coals using lime-based products / R.M. Singh, M. Kamide, T. Li, H. Kim // Environmental science \& technology. - 2005. - V. 39. - P. 4265-4269.

22. Rikker Y.O., Kobylkin M.V., Batukhtin A.G. Improving the efficiency of flue gas desulphurization of TPS // IOP Conference Series: Materials Science and Engineering. - 2019. - V. 552. 012024.

23. Риккер Ю.О., Кобылкин М.В. Обзор современных технологий очистки дымовых газов ТЭС от окислов серы // Энергетика в современном мире. - Чита: Забайкальский государственный университет, 2017. - С. 92-96.

24. R Jamil., Ming L., Jamil I. Application and development trend of flue gas desulfurization (FGD) process: a review // International Journal of Innovation and Applied Studies. - 2013. - V. 4. P. 286-297.

25. Калинина А.С., Романович Д.А., Тринченко А.А. Современное состояние проблемы сероочистки дымовых газов тепловых электрических станций // Труды СПбГТУ. - 2013. № 515. - C. 45-50.

26. Narayanan K.V., Natarajan E. Experimental studies on cofiring of coal and biomass blends in India // Renewable Energy. - 2007. V. 32. - P. 2548-2558.

27. Carbon, sulfur and nitrogen oxide emissions from combustion of pulverized raw and torrefied biomass / X. Ren, R. Sun, X. Meng, N. Vorobiev, M. Schiemann, Y.A. Levendis // Fuel. - 2017. V. 188. - P. 310-323.

28. Co-combustion characteristics and blending optimization of tobacco stem and high-sulfur bituminous coal based on thermogravimetric and mass spectrometry analyses / K. Zhang, Y. Cao, W.P. Pan // Bioresource technology. - 2013. - V. 131. P. 325-332.

29. Co-combustion of wheat straw and camphor wood with coal slime: thermal behaviour, kinetics, and gaseous pollutant emission characteristics / L. Xinjie, Z. Shihong, W. Xincheng, S. Jinai, Z. Xiong, W. Xianhua, C. Hanping // Energy. - 2021. - V. 234. 121292.

30. Experimental study of the processes of reducing the formation of sulfur oxides during the co-combustion of particles of metalignitous coal and wood processing waste / S.A. Yankovsky, G.V. Kuznetsov, A.A. Tolokolnikov, I.V. Cherednik, A.A. Ivanov // Fuel. - 2021. - V. 291. - 120233. 
31. Торфяная промышленность России и мира. Анализ состояния и перспективы развития / Г.Ю. Боярко, П.В. Бернатонис В.К. Бернатонис // Минеральные ресурсы России. Экономика и управление. - 2014. - №. 6. - С. 56-61.

32. Paappanen T., Leinonen A., Hillebrand K. Fuel peat industry in EU. Summary report. - Jyväskylä: Technical Research Centre of Finland, 2006. -235 p.

33. Life-cycle climate impacts of peat fuel: calculation methods and methodological challenges / J. Grönroos, J. Seppälä, S. Koskela A. Kilpeläinen, P. Leskinen, A. Holma, J. Turunen, S. Lind, M. Maljanen, PJ. Martikainen. // The International journal of life cycle assessment. - 2013. - V. 18. - P. 567-576.

34. Предприятия топливообеспечения и потенциальные возобновляемые ресурсы местного топлива по регионам Российской Федерации // Федеральная служба государственной статистики (форма 1-П) с 2000 по 2009 гг.

35. Торфяные ресурсы Томской области и их использование / Л.И. Инишева, В.С. Архипов, С.Г. Маслов, Л.С. Михантьева. Новосибирск: Изд-во СО РАН, 1995. - 88 с.

36. The study of highly mineralized peat sedimentation products in terms of their use as an energy source / R. Tabakaev, K. Ibraeva,
N. Yazykov, I. Shanenkov, Y. Dubinin, A. Zavorin // Fuel. 2020. - V. 271. - 117593.

37. Исследование характеристик и минерального состава торфа Томской области применительно к энергетическому использованию / К.Т. Ибраева, Ю.О. Манаев, Р.Б. Табакаев, Н.А. Языков, А.С. Заворин // Известия Томского политехнического университета. Инжиниринг георесурсов. - 2019. T. 330. - № 1. - C. 191-200.

38. Combustion of bituminous coal and semicoke with copper salts / K.B. Larionov, I.V. Mishakov, K.V. Slyusarskiy, S.A. Tsibulskiy, R.B. Tabakaev, Y.I. Bauman, A.A. Gromov // Fuel Processing Technology. - 2021. - V. 213. - 106706.

39. Энергетическое топливо СССР. Ископаемые угли, горючие сланцы, торф, мазут и горючий газ: справочник / В.С. Вдовченко, М.И. Мартынов, Н.В. Новицкий, Г.Д. Юшина. М.: Энергоатомиздат, 1991. - 183 с.

40. Тепловой расчет котлов: нормативный метод. - СПб.: Изд-во НПО ЦКТИ, 1998. - 256 с.

41. Фурсов И.Д. Конструирование и тепловой расчет паровых котлов. - Барнаул: Изд-во АлтГТ, 2016. - 297 с.

Поступила 13.10.2021 2.

\section{Информация об авторах}

Tабакаев P.Б., кандидат технических наук, старший научный сотрудник Тюменского государственного университета.

Ларионов К.Б., кандидат технических наук, доцент научно-образовательного центра И.Н. Бутакова Инженерной школы энергетики Национального исследовательского Томского политехнического университета.

Ибраева К.T., аспирант, инженер научно-образовательного центра И.Н. Бутакова Инженерной школы энергетики Национального исследовательского Томского политехнического университета; инженер-исследователь Тюменского государственного университета.

Шаненков И.И., кандидат технических наук, доцент отделения электроэнергетики Инженерной школы энергетики Национального исследовательского Томского политехнического университета.

Заворин A.C., доктор технических наук, профессор, заведующий кафедрой - руководитель научнообразовательного центра И.Н. Бутакова на правах кафедры Инженерной школы энергетики Томского политехнического университета. 
UDC $662.7 ; 662.641$

\section{CARBON RESIDUAL FROM THE THERMAL PROCESSING OF OIL SLUDGE AS THE BASIS FOR A FUEL COMPOSITION}

Roman B. Tabakaev1,
TabakaevRB@tpu.ru

Kirill B. Larionov², larryk@tpu.ru

\author{
Kanipa T. Ibraeva2,1, \\ kti1@tpu.ru
}

\section{Ivan I. Shanenkov²,} shanenkovii@tpu.ru

\author{
Alexander S. Zavorin², \\ zavorin@tpu.ru \\ 1 University of Tyumen, \\ 6, Volodarsky street, Tyumen, 625003, Russia. \\ 2 National Research Tomsk Polytechnic University, \\ 30, Lenin avenue, Tomsk, 634050, Russia.
}

The relevance of the research is caused by the interest in ensuring the thermal costs of oil refining technologies at the expense of byproducts (oil sludge), as well as the need to reduce harmful emissions of technological processes.

The main aim is research of the possibility of burning the carbon residue obtained during steam gasification of oil sludge as part of a fuel composition with the addition of peat.

Objects of the research are carbon residue of oil sludge obtained after steam gasification of oil sludge at $600{ }^{\circ} \mathrm{C}$, and a fuel composition based on it with the addition of peat ( $25 \mathrm{wt}$. \%).

Methods. Thermotechnical characteristics of the studied samples are determined according to SS R 55661-2013, 33503-2015 and 55660-2013. Net calorific values of the peats were determined in the ABK-1 calorimeter (Russia), the elemental composition of the organic matter was determined using the analyzer Vario Micro Cube (Elementar, Germany). Particle size (CROS) was determined using a scanning electron microscope JSM-6000C (JEOL, Japan). The study of the combustion of the samples under consideration was carried out using the differential thermal analyzer STA 449 F3 Jupiter (Netzsch, Germany) and an experimental stand equipped with a high-speed video camera FASTCAM CA4 5 (Photron, USA). The characteristic melting temperatures of ash and its composition are determined according to the SS 2057-94 and the SS 10538-87, respectively.

Results. The carbon residue has a calorific value exceeding peat and comparable to brown coals and a rather low ignition temperature $\left(220^{\circ} \mathrm{C}\right)$, which is due to a rather high content of volatile substances $\left(V^{d a f}=64,3 \%\right)$. However, high values of ash content $\left(A^{d}=60 \%\right)$ and sulfur content $\left(S^{d a f}=4,3 \%\right)$ indicate the need to dispose of a large amount of ash and capture sulfur oxides SOx. It is shown that the joint combustion of carbonaceous residue and peat ( $25 \mathrm{wt}$. \%) allowed reducing the amount of ash residue formed. In addition, when adding $25 \mathrm{wt}$. \% of sukhovskoy peat it was possible to reduce the amount of generated $\mathrm{SO}_{2}$ emissions by more than 3 times. This effect is due to the gas phase interaction with peat mineral part, namely, with calcium and magnesium carbonates.

\section{Key words:}

Oil sludge, carbon residue, highly mineralized peat, fuel composition, combustion, emissions of sulfur oxides.

This work was supported by the Russian Foundation for Basic Research (project no. 19-38-90148). Analytical measurements were carried out in the laboratory of resource-efficient technologies for thermal processing of biomass within the framework of a state assignment (topic: "Development of a waste-free technology for thermal processing of biomass into solid and gaseous products to provide energy and industry with products that reduce their carbon footprint»).

\section{REFERENCES}

1. IEA Online Data Services. Renewables Information. Available at: https://www.iea.org/fuels-and-technologies/electricity.html (accessed 11 August 2021)

2. Li J., Lin F., Xiang L., Zheng F., Che L., Tian W., Chen G. Hazardous elements flow during pyrolysis of oily sludge. Journal of Hazardous Materials, 2021, vol. 409, 124986.

3. Santiago Y.C., González A.M., Venturini O.J., Maya D.M.Y. Assessment of the energy recovery potential of oil sludge through gasification aiming electricity generation. Energy, 2021, vol. 215. 119210.

4. Chu Z., Gong Z., Wang Z., Zhang H., Wu J., Wang Z., Wang H. Experimental study on kinetic characteristics of oil sludge gasifi- cation. Asia-Pacific Journal of Chemical Engineering, 2021, vol. 16, pp. 1-11.

5. Mazlova E.A., Meshcheryakov S.V. Ecological characteristics of oil sludges. Chemistry and technology of fuels and oils, 1999, vol. 35, pp. 49-53.

6. Zhuravskii G.I. Fuel from oil sludges. Journal of Engineering Physics and Thermophysics, 2019, vol. 92, pp. 940-947.

7. Zhou L., Jiang X., Liu J. Characteristics of oily sludge combustion in circulating fluidized beds. Journal of hazardous materials, 2009, vol. 170, pp. 175-179.

8. Milhé M., Van de Steene L., Haube M., Commandré J.M., Fassinou W.F., Flamant G. Autothermal and allothermal pyrolysis in a 
continuous fixed bed reactor. Journal of Analytical and Applied Pyrolysis, 2013, vol. 103, pp. 102-111.

9. Razva A.S. Metody i tekhnologii ochistki dymovykh gazov ot oksidov sery [Methods and technologies for cleaning flue gases from sulfur oxides]. 2010. Studopediya. Available at http://studopedia.ru/5_16593_metodiochistki-dimovih-gazov-otoksidov-seri. html (accessed 19 August 2021).

10. Ding Q., Tang X.F., Yang Z.G. Failure analysis on abnormal corrosion of economizer tubes in a waste heat boiler. Engineering Failure Analysis, 2017, vol. 73, pp. 129-138.

11. Solovyev A.K., Mikheev V.O., Pulikov P.S. Ochistka dymovykh gazov ot oksidov sery [Flue gas purification from sulfur oxides] Vestnik Sibirskogo gosudarstvennogo industrialnogo universiteta, 2014, no. 3 (9), pp. 33-36.

12. Yeau K.Y., Kim E.K. An experimental study on corrosion resistance of concrete with ground granulate blast-furnace slag. $\mathrm{Ce}$ ment and Concrete Research, 2005, vol. 35, pp. 1391-1399.

13. Golubykh N.D., Zherebyateva T.V., Korneev A.D. Biodestruktsiya gidrosilikatov stroitelnykh materialov [Biodestruction of hydrosilicates of building materials]. Nauchny vestnik Voronezhskogo gosudarstvennogo arkhitekturno-stroitelnogo universiteta. Stroitelstvo i arkhitektura, 2009, no. 3, pp. 54-60.

14. Lasek J.A., Kazalski K. Sulfur self-retention during cocombustion of fossil fuels with biomass. Energy \& fuels, 2014, vol. 28, pp. 2780-2785.

15. Gritsenko A.B., Vnukova N.V., Pozdnyakova E.I. Sovmestnoe szhiganie produktov piroliza shin i drevesnykh pellet $[\mathrm{Co}-$ incineration of pyrolysis products of tires and wood pellets]. Energetika. Izvestiya vysshikh uchebnykh zavedeniy i energeticheskikh obedineniy SNG, 2021, no. 4, pp. 363-376.

16. Karp I.N., Martsevoy E.P., Pyanyh K.E., Antoshchuk T.A., Pyanyh K.K. Research and implementation of coal and biomass gasification processes to replace natural gas. Energy technologies and resource conservation, 2014, no. 4, pp. 3-13. In Rus.

17. Zhang H., Gong Z., Liu L., Wang Z., Li X. Study on the migration characteristics of sulfur and nitrogen during combustion of oil sludge with $\mathrm{CaO}$ additive. Energy \& Fuels, 2020, vol. 34, pp. 6124-6135.

18. Kislov V.M., Tsvetkova Yu.Yu., Tsvetkov M.V., Pilipenko E.N., Salganskaya M.V. Sulfur compounds neutralization at filtration combustion of sulfur coals by addition of calcium-based materials. Combustion and plasma chemistry, 2020, vol. 18, no. 3, pp. 127-132. In Rus.

19. Wu G.L., Guo R.T., Liu Y.Z., Duan C.P., Miao Y.F., Gu J.W., Pan W.G. Effects of $\mathrm{CaO}-\mathrm{MgCO}_{3}$ on the combustion behavior and emission properties of SO2 and NOx during semi-coke combustion. Chemical Papers, 2021, vol. 75, pp. 2495-2501.

20. Arbuzov V.A., Isanova B.H., Belyakova M.O., Zadiranov A.N Ochistka dymovykh gazov TETs ot oksidov sery i azota [Purification of flue gases of thermal power plants from sulfur and nitrogen oxides]. Lityo i metallurgiya, 2009, no. 3, pp. 99-103.

21. Singh R.M., Kamide M., Li T., Kim H. Combustion properties and desulfurization of high sulfur containing indian and nepali coals using lime-based products. Environmental science \& technology, 2005 , vol. 39, pp. 4265-4269.

22. Rikker Y.O., Kobylkin M.V., Batukhtin A.G. Improving the efficiency of flue gas desulphurization of TPS. IOP Conference Series: Materials Science and Engineering, 2019, vol. 552, 012024.

23. Rikker Yu.O., Kobylkin M.V. Obzor sovremennykh tekhnologiy ochistki dymovykh gazov TES ot okislov sery [Overview of modern technologies for cleaning flue gases of thermal power plants from sulfur oxides]. Energetika $v$ sovremennom mire [Energy in the modern world]. Chita, Transbaikal State University Publ., 2017 pp. 92-96.

24. Jamil R., Ming L., Jamil I. Application and development trend of flue gas desulfurization (FGD) process: a review. International Journal of Innovation and Applied Studies, 2013, vol. 4, pp. 286-297.

25. Kalinina A.S., Romanovich D.A. Trinchenko A.A. Sovremennoe sostoyanie problemy seroochistki dymovykh gazov teplovykh elektricheskikh stantsii [The current state of the problem of desulfu- rization of flue gases of thermal power plants]. Trudy SPbGTU, 2013 , no. 515 , pp. $45-50$.

26. Narayanan K.V., Natarajan E. Experimental studies on cofiring of coal and biomass blends in India. Renewable Energy, 2007, vol. 32 pp. 2548-2558.

27. Ren X., Sun R., Meng X., Vorobiev N., Schiemann M., Levendis Y.A. Carbon, sulfur and nitrogen oxide emissions from combustion of pulverized raw and torrefied biomass. Fuel, 2017, vol. 188, pp. 310-323.

28. Zhang K., Cao Y., Pan W.P. Co-combustion characteristics and blending optimization of tobacco stem and high-sulfur bituminous coal based on thermogravimetric and mass spectrometry analyses. Bioresource technology, 2013, vol. 131, pp. 325-332.

29. Xinjie L., Shihong Z., Xincheng W., Jinai S., Xiong Z., Xianhua W., Hanping C. Co-combustion of wheat straw and camphor wood with coal slime: thermal behaviour, kinetics, and gaseous pollutant emission characteristics. Energy, 2021, vol. 234, 121292.

30. Yankovsky S.A., Kuznetsov G.V., Tolokolnikov A.A., Cherednik I.V., Ivanov A.A. Experimental study of the processes of reducing the formation of sulfur oxides during the co-combustion of particles of metalignitous coal and wood processing waste. Fuel, 2021, vol. 291, 120233.

31. Boyarko G.Yu., Bernatonis P.V., Bernatonis V.K. Peat industry of Russia and the world. Analysis of the state and prospects of development. Mineral resources of Russia. Economics and Management, 2014, no. 6, pp. 56-61. In Rus.

32. Paappanen T., Leinonen A., Hillebrand K. Fuel peat industry in EU. Summary report. Jyväskylä, Technical Research Centre of Finland, 2006. $235 \mathrm{p}$.

33. Grönroos J., Seppälä J., Koskela S., Kilpeläinen A., Leskinen P., Holma A., Turunen J., Lind S., Maljanen M., Martikainen P.J. Life-cycle climate impacts of peat fuel: calculation methods and methodological challenges. The International journal of life cycle assessment, 2013, vol. 18, pp. 567-576.

34. Predpriyatiya toplivoobespecheniya $i$ potentsialnye vozobnovlyaemye resursy mestnogo topliva po regionam Rossiyskoy Federatsii. Federalnaya sluzhba gosudarstvennoy statistiki (forma 1-P) $s 2000$ po $2009 \mathrm{gg}$. [Fuel supply enterprises and potential renewable resources of local fuel in the regions of the Russian Federation].

35. Inisheva L.I., Arkhipov V.S., Maslov S.G., Mikhantyeva L.S. Torfyanye resursy Tomskoy oblasti $i$ ikh ispolzovanie [Peat resources of the Tomsk region and their use]. Novosibirsk, SO RAN Publ., 1995. 88 p.

36. Tabakaev R., Ibraeva K., Yazykov N., Shanenkov I., Dubinin Y., Zavorin A. The study of highly mineralized peat sedimentation products in terms of their use as an energy source. Fuel, 2020, vol. 271, 117593 .

37. Ibraeva K.T., Manaev Yu.O., Tabakaev R.B., Yazykov N.A., Zavorin A.S. Study of the characteristics and mineral composition of peat of the Tomsk region in relation to energy use. Bulletin of the Tomsk Polytechnic University. Geo Assets Engineering, 2019, vol. 330, no. 1, pp. 191-200. In Rus.

38. Larionov K.B., Mishakov I.V., Slyusarskiy K.V., Tsibulskiy S.A., Tabakaev R.B., Bauman Y.I., Gromov A.A. Combustion of bituminous coal and semicoke with copper salts. Fuel Processing Technology, 2021, vol. 213, 106706.

39. Vdovchenko V.S. Martynov M.I., Novitsky N.V., Yushina G.D. Energeticheskoe toplivo SSSR. Iskopaemye ugli, goryuchie slantsy, torf, mazut $i$ goryuchiy gaz: spravochnik [Energy fuel of the USSR. Fossil coals, oil shale, peat, fuel oil and combustible gas: reference]. Moscow, Energoatomizdat Publ., 1991. 183 p.

40. Teplovoy raschet kotlov: normativny metod [Thermal calculation of boilers: a normative method]. St-Petersburg, NPO TSKTI Publ., 1998. $256 \mathrm{p}$

41. Fursov I. D. Konstruirovanie i teplovoy raschet parovykh kotlov [Design and thermal calculation of steam boilers]. Barnaul, AltSTU Publ., 2016. 297 p.

Received: 13 October 2021. 


\section{Information about the authors}

Roman B. Tabakaev, Cand. Sc., senior researcher, University of Tyumen.

Kirill B. Larionov, Cand. Sc., associate professor National Research Tomsk Polytechnic University.

Kanipa T. Ibraeva, postgraduate student, National Research Tomsk Polytechnic University; research engineer, University of Tyumen.

Ivan I. Shanenkov, Cand. Sc., associate professor, National Research Tomsk Polytechnic University. Alexander S. Zavorin, Dr. Sc., professor, National Research Tomsk Polytechnic University. 